\title{
Clinical and Laboratory Evaluation between Serum Cholesterol and Thyroid Stimulating Hormone Level in the Patients of Thyroid Dysfunction and Hypothyroidism
}

\author{
Himani Pundir ${ }^{1}(\mathbb{D})$, Siddhartha Dan 2,*(D), Sunita Manhas ${ }^{3, *(\mathbb{D})}$ \\ 1 Department of Biochemistry, N.C. Medical College and Hospital, Israna, Panipat, Haryana, 132107, India; \\ himanipundir28897@gmail.com (H.P.); \\ 2 Department of Biotechnology, I.K. Gujral Punjab Technical University, Jalandhar, Punjab, 144603, India; \\ siddharthadan7@gmail.com (S.D.); \\ 3 Department of Biochemistry, Maharishi Markandeshwar Institute of Medical Science and Research, MMDU, Mullana, \\ Haryana, 13320, India; sunitamanhas@yahoo.com (S.M.); \\ * Correspondence: sunitamanhas@yahoo.com (S.M.); siddharthadan7@gmail.com (S.D.);
}

Scopus Author 57218994496

Received: 10.05.2021; Revised: 10.06.2021; Accepted: 15.06.2021; Published: 27.06.2021

\begin{abstract}
Thyroid hormones regulate lipid and lipoprotein metabolism; Therefore, thyroid dysfunction induces significant changes in lipid levels. This study was carried out to study the prevalence of thyroid disease and observe the association between hypothyroidism and serum cholesterol levels. A crosssectional study enrolling all 50 diagnosed hypothyroid patients coming to the hospital lab irrespective of age and sex was selected, conducted during 2018-2020. The present study was conducted in the department of biochemistry in fifty hypothyroid male and female cases and 50 healthy controls. Serum triiodothyronine (T3), thyroxine (T4), thyroid-stimulating hormone (TSH), Total cholesterol, lowdensity lipoprotein (LDL) cholesterol, high-density lipoprotein (HDL) cholesterol, and Triglycerides were estimated in these patients, and the results were analyzed. Mean values of Serum Cholesterol in cases $(<0.001)$, there was a significant difference between serum cholesterol of hypothyroid cases and controls with p-value $<0.001$. There was a significant difference between serum TSH of hypothyroid cases and controls with a p-value $<0.000$. We found that in other investigations FBS, TG, VLDL, T3 \& $\mathrm{T} 4$, the p-value was found significant among cases and controls. In the present study, we concluded that TSH level is increased and T3 and T4 levels are decreased in hypothyroid patients, creatinine, and cholesterol levels are increased in hypothyroid patients. We observed that there is an increase in TSH levels as age increases. We can say that any change in thyroid hormone levels alters skeletal muscles' functioning and decreases renal perfusion and filtration capacity.
\end{abstract}

Keywords: cholesterol; thyroid stimulating hormone; thyroid dysfunction; hypothyroidism.

(C) 2021 by the authors. This article is an open-access article distributed under the terms and conditions of the Creative Commons Attribution (CC BY) license (https://creativecommons.org/licenses/by/4.0/).

\section{Introduction}

Hypothyroidism is the most common endocrine disorder all over the world [1]. In this endocrine disorder, there occurs a decrease in the production of thyroid hormones by the thyroid gland. The prevalence of hypothyroidism ranges from $2 \%$ to $15 \%$ in mild and chronic cases, respectively. Any alteration in thyroid hormone level has a profound influence on metabolic processes, consequently damaging various tissues and organs. Decreased metabolic functions in the body, such as impaired carbohydrate, decreased protein turnover, metabolism, etc., were caused by Hypothyroidism [1,2]. 
According to thyroid levels, the subjects are classified into five categories: thyrotoxicosis, subclinical thyrotoxicosis, thyroid, subclinical hypothyroidism, and hypothyroidism. Hypothyroidism is defined as low T3, T4, and increased TSH level, and in the subclinical hypothyroidism, normal T3 and T4 but rise the TSH level and in the subclinical thyrotoxicosis decreased level of TSH and normal T3, T4 level and in the thyrotoxicosis high FT3, FT4 level with decrease the TSH level [3]. In some cases, the sole clinical manifestation of hypothyroidism may be hypothyroid, with a rise in serum creatine kinase (CK) activity and a rise in aldoses or lactate dehydrogenase enzyme activity. In the subjects of hypothyroidism, the major source of increased plasma creatine kinase (CK) level may be skeletal muscle. Evaluating total $\mathrm{CK}$ activity is considered a good biochemical marker or sensitive marker for diagnosing neuromuscular diseases [4]. An increase in the level of these enzymes represents cellular necrosis and tissue damage. The thyroid hormones are required for the growth and development of the kidney. They maintain water and electrolyte balance. The kidneys have an important role in the metabolism, elimination, and also synthesis of thyroid hormones [5]. Thyroid dysfunction affects renal function by altering the renal blood flow, GFR, electrolyte homeostasis. Creatine is synthesized in the kidney and liver then passes into the blood circulation. About $2 \%$ of total creatine is converted to creatinine per day (females $0.4-1.2 \mathrm{mg} / \mathrm{dl}$ and males $0.7-1.5 \mathrm{mg} / \mathrm{dl}$ ) [6]. The amount of creatinine produced is related to the total muscle mass and remains the same in the plasma and urine daily. Serum creatinine level is a sensitive index of renal function. Creatinine clearance (females $85-130 \mathrm{ml} / \mathrm{min}$ males $95-140 \mathrm{ml} / \mathrm{min}$ ) is a fine measure of GFR [7].

In hypothyroidism, creatinine level increases due to muscle dystrophy [8]. Although freely filtered, additional tubular secretion of creatinine renders it a poor marker of GFR. In patients with hypothyroidism, clarification of whether an elevated serum creatinine represents true renal impairment (i.e., reduced GFR) or simply increased generation, and tubular secretion, of creatinine, therefore, requires further analysis by way of isotope GFR studies [9]. Hypothyroidism is associated with many biochemical abnormalities, including increased serum uric acid and creatinine levels. The serum creatinine and serum creatine kinase concentration rose in hypothyroid patients due to a decrease of glomerular filtration rate because of hemodynamic changes in severe hypothyroidism [10]. Hypothyroidism is associated with hyperuricemia. When compared with previous reports, the prevalence of a significant increase in hyperuricemia and gout was found in hypothyroid patients [11].

Kreisman and Hennessey et al. suggest the presence of elevated mean serum creatinine levels in hypothyroid subjects compared to euthyroid controls [12]. This finding was corroborated by a Swiss study that found increased creatinine levels responding to thyroid hormone therapy in newly diagnosed hypothyroid subjects [13]. Autoimmune disorders associated with hypothyroidism may additionally impact actual renal function and elevate serum creatinine [14].

Now, we have concluded that after the present study, cholesterol levels are increased in hypothyroid patients. We observed that there is an increase in TSH levels as age increases. It can be said that any change in thyroid hormone levels decreases renal perfusion and filtration capacity. In hypothyroidism, renal dysfunction occurs. Abnormal thyroid hormone profile in blood without any underlying thyroid gland disorder can occur in chronic renal disorders, causing difficulty and errors in their interpretation. Our data highlight that CKD leads to a significant lowering of free thyroid hormone levels, with a reduction correlating with the severity of the renal disease. This project emphasizes the importance of thyroid hormone 
estimation and exercising adequate care in interpreting their results in patients with CKDs. Further larger studies evaluating the clinical significance of thyroid hormone status in CKD patients would enhance our understanding of the subject.

Patients having chronic kidney disease (CKD) are exposed to develop coronary artery disease. CVD and CKD are due to inflammations and have a bad impact on lipid status. Increased lipid levels in CKD (elevated triglycerides) increased high-density lipoproteins; both are said to be dysfunctional. These dysfunctional high-density lipoproteins are proinflammatory. They lose their atheroprotective capability, and cholesterol is effluxed from the cells. There is also lipid-overload in macrophages in the arterial wall. Increased triglycerides are primarily from defective clearance. There is a weak association between low-density lipoprotein cholesterol level and coronary risk in CKD, and it has led to controversy over the effectiveness of statin therapy. There is disrupted cholesterol transport in CKD, presenting both clinical and pre-clinical evidence of the uremic environment's impact on vascular lipid accumulation. Preventative and treatment strategies are explored [15].

Although thyroid dysfunction impacts various organ systems of the body, the present study was carried out to see the impact of thyroid disorder on serum cholesterol and blood urea. Our study finds that the correlation between serum creatinine levels in hypothyroid patients was increased. Cholesterol levels in hypothyroid patients also were increased.

\section{Materials and Methods}

\subsection{Study design.}

A cross-sectional study enrolling all 50 diagnosed hypothyroid patients coming to the hospital lab irrespective of age and sex was selected, conducted during 2018-2020 at our center Department of Biochemistry in collaboration with the Department of General Medicine, M.M. Institute of Medical Sciences and Research, Mullana, Ambala was designed. The diagnosis of hypothyroidism was made based on hospital lab thyroid profile results. The study was conducted among patients attending the medicine OPD for the management of hypothyroid diseases. A minimum of 50 patients were selected for the study as per controls and patients. According to our study's inclusion criteria, the patients with hypothyroid diseases and either sex (male and female) and the exclusion criteria in patients with renal disease, Patients on treatment for hyperlipidemia, and Subjects not willing to participate.

One pre-tested questionnaire was used to determine hypothyroid disease in patients attending the medicine OPD in M.M.I.M.S.R., Mullana, Ambala. It contains three sections, i.e., Section (A) Personal details, Section (B) Risk factor details, and Section (C) Laboratory investigations. The study was conducted after obtaining informed and written consent from the individual following whom the study participant was assessed using a questionnaire tool as stated above.

\subsection{Patients.}

The present study was conducted in the department of biochemistry in fifty hypothyroid male and female cases and 50 healthy controls. The majority of the cases were in the age group 32-60 years and controls 18-31years. 


\subsection{Laboratory measurements.}

For laboratory measurements, $5 \mathrm{ml}$ of venous blood sample was collected from the antecubital vein of the subjects in a disposable syringe under aseptic conditions and transferred to a sterile, dry, and acid-washed vial for biochemical analysis. The blood was allowed to stand for half an hour. After the clot formation, the supernatant was centrifuged to perform the following biochemical investigations, i.e., Serum Cholesterol was estimated by the CHODPAP method, and Serum TSH was estimated by the ERBA method.

Fasting blood sugar, serum cholesterol, high-density lipoprotein (HDL), low-density lipoprotein (LDL), very-low-density lipoprotein (VLDL), and triglyceride levels were measured using an equipment Analyser, Erba.

\subsubsection{Serum cholesterol.}

In this method, proteins in serum are precipitated with ferric chloride acetic acid reagent. The protein-free filtrate containing cholesterol is treated with concentrated sulphuric acid. Cholesterol in the presence of sulphuric acid undergoes dehydration to form 3,5 cholestadiene. This is, in turn, oxidized and sulfonated to form red color cholestapolyene sulphonic acid in the presence of $\mathrm{Fe}^{3+}$ ions. The intensity of the red color formed is proportional to the amount of cholesterol present in the serum. The color intensity is measured by using a green filter $(540 \mathrm{~nm})$. Now we prepare protein-free filtrate, pipette $0.1 \mathrm{ml}$ of serum into a dry test tube, and add $9.9 \mathrm{ml}$ of ferric chloride acetic acid reagent. Mix well by using a glass rod and be allowed to stand for 10 to 15 minutes. Filter into a dry test tube then development of color, label three test tube as $\mathrm{B}, \mathrm{S}$ and $\mathrm{T}$. pipette $5 \mathrm{ml}$ ferric chloride acetic acid reagent into $\mathrm{B}$, $5 \mathrm{ml}$ standard cholesterol solution into $\mathrm{S}$ and $5 \mathrm{ml}$ protein-free filtrate into $\mathrm{T}$. to all the tubes, add $3 \mathrm{ml}$ of concentrated sulphuric acid. Mix by swirling. Let stand for 20 to 30 minutes. Read the optical by using a green filter $(540 \mathrm{~nm})$ ane in table 1 . Mix well and keep at room temperature 20 to $30 \mathrm{~min}$.

\subsubsection{Cholesterol stock solution.}

Dissolve $40 \mathrm{mg}$ of cholesterol in $100 \mathrm{ml}$ of ferric chloride acetic acid reagent. Working standard solution: Dilute $10 \mathrm{ml}$ of stock solution to $100 \mathrm{ml}$ with ferric chloride acetic acid reagent, i.e. $4 \mathrm{mg} / 100 \mathrm{ml}$ i.e. $0.2 \mathrm{mg} / 5 \mathrm{ml}$.

The volume of the test sample, $10 \mathrm{ml}$ of protein-free filtrate contain, i.e., $0.1 \mathrm{ml}$ serum $\& 5 \mathrm{ml}$ of protein-free filtrate contain, i.e., $0.05 \mathrm{ml}$ serum. The glassware used in this estimation should be absolutely dry. Ferric chloride acetic acid reagent is unstable. So, use fresh reagent in the assay. The normal value of serum cholesterol is $150-250 \mathrm{mg} / \mathrm{dl}$, Borderline High is 200$239 \mathrm{mg} / \mathrm{dl}$, and High is $240 \mathrm{mg} / \mathrm{dl}$ or Greater.

Principle of Immunoenzymometric assay, Essential reagent required for an immuneenzymometric assay includes a high affinity and specific antibody (enzyme-conjugated and immobilized) with different and distinct epitope recognition in excess and native antigen. In this procedure, immobilization occurs during the assay at the surface of a microplate well through the interaction of anti-TSH coated on the well and exogenously added monoclonal ANTI-TSH antibody. Upon mixing monoclonal biotinylated antibody, enzyme-labeled antibody, and a serum containing native antigen, the reaction results between the native antigen and the antibodies, without competition or steric hindrance to form a soluble sandwich complex. After equilibrium is obtained, the antibody-bound fraction is separated from the 
unbound antigen by decantation or aspiration. The enzyme activity in antibody-bound fractions is directly proportional to the native antigen concentration. By utilizing several different serum references of known antigen values, a dose-response curve can be generated from which antigen concentration of unknown can be ascertained.

Table 1. Reagents volume of test, standard and blank for the analyzer.

\begin{tabular}{l|l|l|l} 
Reagent & Test & Standard & Blank \\
\hline Cholesterol reagent & $2.5 \mathrm{ml}$ & $2.5 \mathrm{ml}$ & $2.5 \mathrm{ml}$ \\
\hline Protein Free Filtrate & $1 \mathrm{ml}$ & - & - \\
\hline Standard & - & $0.1 \mathrm{ml}$ & - \\
\hline Distilled Water & - & - & $0.1 \mathrm{ml}$
\end{tabular}

\subsection{Test procedure and calculation.}

Before proceeding with the assay, all reagents, serum references, and controls were brought to room temperature (20-30c). The well of the microplate was labeled for each serum reference, control, and patient specimen to be assayed in duplicate. Any unused microwell strips were replaced back into the aluminum bag, sealed, and stored at 2-8c. $0.025 \mathrm{ml}(25 \mathrm{ul})$ of the appropriate serum reference, control, and specimen were pipetted into the assigned well and then incubated for 10 minutes at room temperature. $0.100 \mathrm{ml}(100 \mathrm{ul})$ of the conjugate was added to each well. The microplate was swirled gently for 10 seconds to mix and then covered and then incubated for 90 minutes at room temperature. The content of the microplate was discarded by decantation. $300 \mathrm{ul}$ of wash buffer was added and then removed by tapping. It was repeated four additional times for a total of five washes. $0.100 \mathrm{ml}$ (100ul) of TMB substrate was added solution to all wells. All reagent was added in the same order to minimize reaction time differences between wells, then incubated at room temperature for 20 minutes. $0.100 \mathrm{ml}$ (100ul) of stop solution was added to each well. Read the absorbance in each well at $450 \mathrm{~nm}$ in a microplate reader.

A dose curve was used to ascertain the concentration of thyrotropin in unknown specimens. The absorbance was recorded, which was obtained from the printout of the microplate reader. The absorbance for each duplicate serum reference versus the corresponding TSH concentration in Uiu/ml was plotted on graph paper. The best-fit curve was drawn through the plotted points. For determination of the concentration of TSH for an unknown, the average absorbance of the duplicates for each unknown was located on the vertical axis of the graph, found the intersecting point on the curve, and read the concentration (in Uiu/ML) for the horizontal axis of the graph.

Table 2. Types of Tests, their methods, normal range and calculation methods.

\begin{tabular}{|c|c|c|c|c|}
\hline Tests & Method & & Normal values & Calculation \\
\hline \multirow[t]{3}{*}{ Blood Glucose } & \multirow{3}{*}{$\begin{array}{lr}\text { Glucose } & \text { oxidase } \\
\text { Peroxidase } & \text { (GOP- } \\
\text { POD) } & \end{array}$} & $\begin{array}{l}\text { Fasting blood } \\
\text { sugar }\end{array}$ & $70-110 \mathrm{mg} / \mathrm{dl}$ & - \\
\hline & & Post prandial & $70-140 \mathrm{mg} / \mathrm{dl}$ & - \\
\hline & & Random & $70-140 \mathrm{mg} / \mathrm{dl}$ & - \\
\hline Triglyceride & $\begin{array}{l}\text { Glycerol Peroxidase } \\
\text { (GPOD) }\end{array}$ & - & $\leq 150 \mathrm{mg} / \mathrm{dl}$ & $\begin{array}{l}\text { Absorbance of test/absorbance of standard } \\
\mathrm{x} \text { concentration of standard (100) }\end{array}$ \\
\hline High-Density Lipoproteins & Cholesterol Oxidase & - & $35-55 \mathrm{mg} / \mathrm{dl}$ & $\begin{array}{l}\text { Absorbance of test/absorbance of standard } \\
\mathrm{x} \text { concentration of standard }(25) \mathrm{x} 2\end{array}$ \\
\hline Low-Density Lipoproteins & - & - & $<140 \mathrm{mg} / \mathrm{dl}$ & Cholesterol-(HDL+VLDL) \\
\hline $\begin{array}{l}\text { Very Low-Density } \\
\text { Lipoproteins }\end{array}$ & - & - & $2-30 \mathrm{mg} / \mathrm{dl}$ & $\mathrm{TG} / 5$ \\
\hline Tri-Iodothyronine $\left(\mathrm{T}_{3}\right)$ & ERBA-thyrokit. & - & $100-200 \mathrm{ng} / \mathrm{dl}$ & - \\
\hline Tetra-Iodothyronine $\left(\mathrm{T}_{4}\right)$ & ERBA-thyrokit. & - & $5-12 \mu \mathrm{g} / \mathrm{dl}$ & - \\
\hline Serum TSH & ERBA-thyrokit. & - & $0.28-5.50 \mathrm{mg} / \mathrm{dl}$ & - \\
\hline
\end{tabular}




\subsection{Statistical analysis.}

Data collected were entered into Microsoft Excel Worksheet and statistically analyzed by using SPSS (Statistical Package for Social Sciences) version 20. The proportion was expressed as a percentage, and the chi-square test was applied to know the association between various variables. For quantitative data, mean, standard means, standard deviation, and t-test were calculated. P-value $<0.05(<0.01)$ was considered as statically significant (highly significant) at $95 \%$ confidence interval.

\section{Results and Discussion}

It was observed that mean Serum Cholesterol in cases $(<0.001)$ was highly significant as compared to controls. The table shows that in controls Mean \pm SD $(161.82 \pm 25.44)$ and in cases Mean \pm SD $(202.62 \pm 47.16)$, the p-value was (0.001), which is highly significant (Figure 1, Table 5). It was observed that mean TSH in cases $(<0.000)$ was highly significant as compared to controls. The table shows that in controls, Mean $\pm \operatorname{SD}(3.47 \pm 1.30)$ and in cases Mean \pm SD (18.44 \pm 14.57$)$ p-value was (0.000), which is highly significant (Figure 2, Table 6). It was observed that mean (FBS) Fasting blood Sugar in cases $(<0.000)$ was highly significant as compared to controls. The table shows that in controls Mean $\pm \operatorname{SD}(96.17 \pm 10.42)$ and in cases Mean \pm SD $107.74 \pm 23.85)$, the p-value was $(0.000)$, which is highly significant (Figure 3, Table 7). It was observed that the mean Triglyceride in cases $(<0.000)$ was highly significant as compared to controls. Table no shows that in controls Mean \pm SD (124.002 \pm $16.77)$ and in cases Mean \pm SD (153.58 \pm 47.03$)$, the p-value was (0.000), which is highly significant (Figure 4, Table 8). It was observed that mean HDL in cases (0.054) was not significant as compared to controls. Table no shows that in controls, Mean \pm SD $(37.96 \pm 8.55)$ and in cases Mean \pm SD $(41.98 \pm 10.91)$ p-value was $(0.054)$, which is not significant (Figure 5 , Table 9). It was observed that mean LDL in cases (0.193) was not significant as compared to controls. Table no shows that in controls, Mean \pm SD $(99.74 \pm 29.18)$ and in cases Mean \pm SD (127.99 \pm 37.72$)$ p-value was (0.193), which is not significant (Figure 6, Table 10). It was observed that mean VLDL in cases $(<0.000)$ was highly significant compared to controls. Table no shows that in controls, Mean \pm SD $(25.08 \pm 3.82)$ and in cases Mean \pm SD $(31.55 \pm 11.68)$ p-value was (0.000), which is highly significant (Figure 7, Table 11).

Table 3. Gender-related frequency distribution of patients and controls with hypothyroidism.

\begin{tabular}{c|c|c} 
Male/ Female & Cases & Control \\
\hline Male & 18 & 29 \\
\hline Female & 32 & 21 \\
\hline Total & 50 & 50
\end{tabular}

Table 4. Age-related distribution of patients and controls with hypothyroidism.

\begin{tabular}{c|c|c} 
Age(Year) & Cases & Control \\
\hline $18-31$ & 14 & 28 \\
\hline $32-60$ & 31 & 22 \\
\hline $60>$ & 5 & ---
\end{tabular}

Table 5. Mean and SD of Serum Cholesterol in healthy controls and cases.

\begin{tabular}{l|c|c|c} 
& Group (n-100) & Mean \pm SD & p value \\
\hline \multirow{2}{*}{ Serum Cholesterol } & Controls (n-50) & $161.82 \pm 25.44$ & $<0.001^{* *}$
\end{tabular}




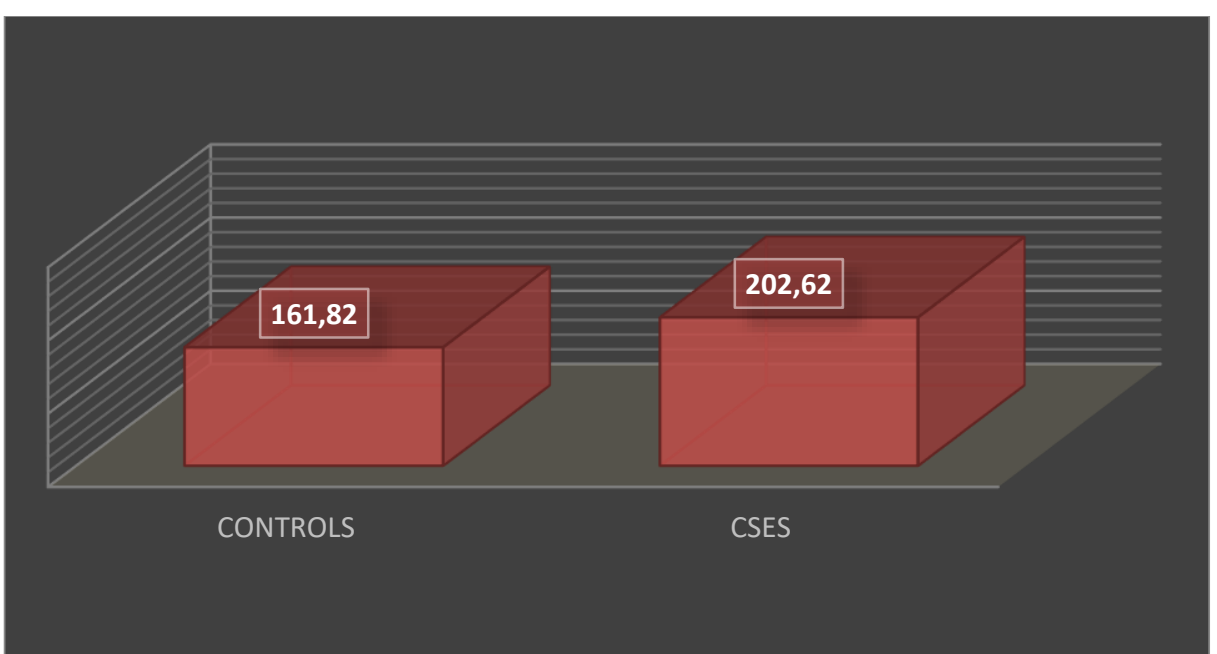

Figure 1. Mean \pm SD of cholesterol in cases and controls.

Table 6. Mean and SD of TSH in healthy controls and cases.

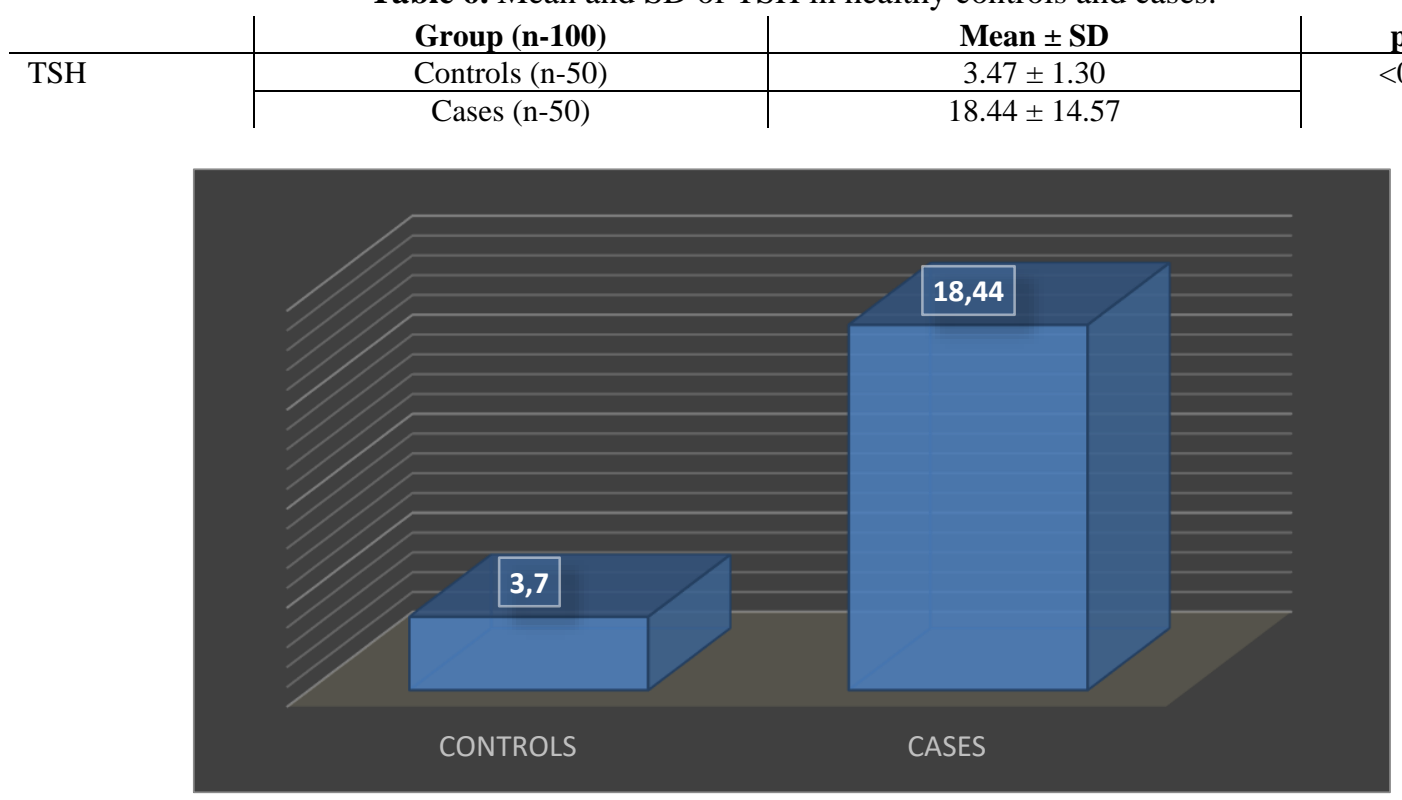

Figure 2. Mean \pm SD of TSH in cases and controls.

Table 7. Mean and SD of FBS (Fasting Blood Sugar) in healthy controls and cases.

\begin{tabular}{l|c|c|c} 
& Group (n-100) & Mean \pm SD & p value \\
\hline Fasting Blood Sugar & Controls $(\mathrm{n}-50)$ & $96.17 \pm 10.42$ & $<0.000^{* *}$
\end{tabular}

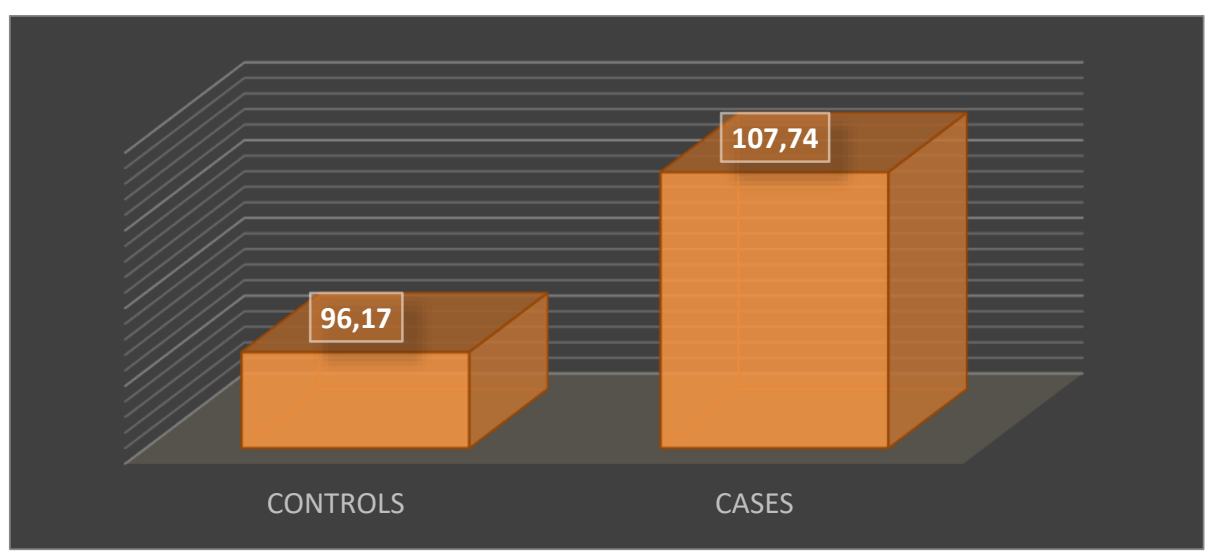

Figure 3. Mean \pm SD of FBS in cases and controls. 
Table 8. Mean and SD of TG (Triglyceride) in healthy controls and cases.

\begin{tabular}{l|c|c|c} 
& Group $(\mathbf{n}-\mathbf{1 0 0})$ & Mean \pm SD & p value \\
\hline Triglyceride & Controls $(\mathrm{n}-50)$ & $124.002 \pm 16.77$ & $<0.000^{* * *}$
\end{tabular}

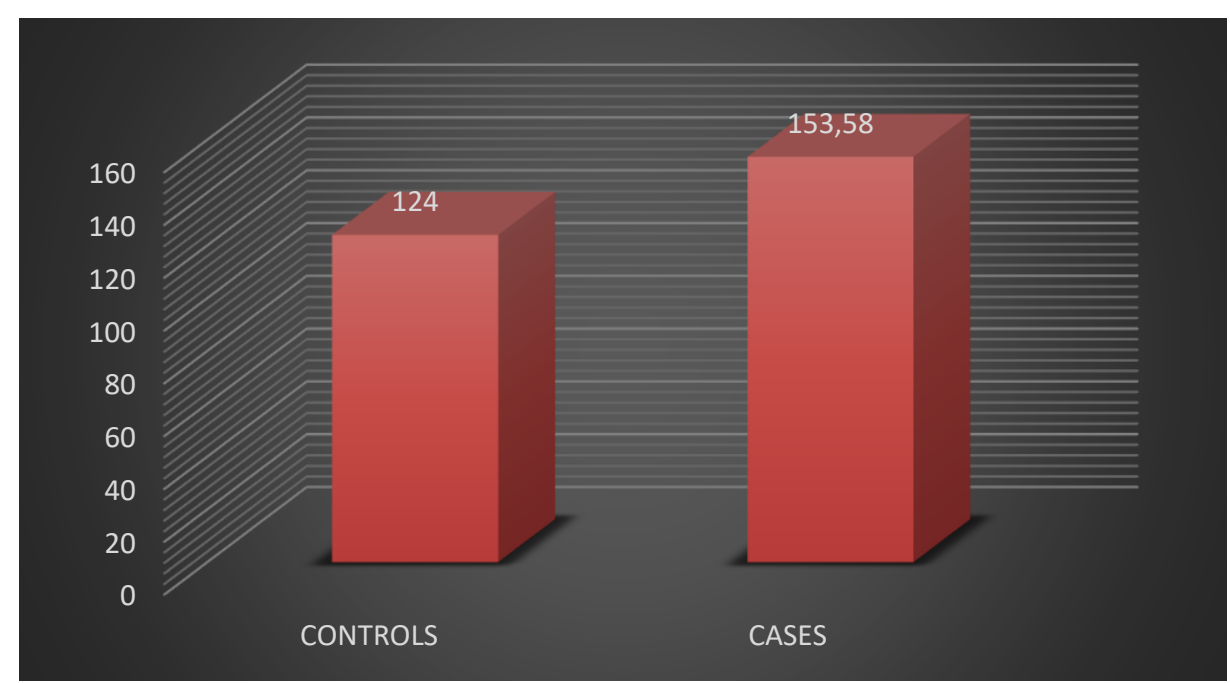

Figure 4. Mean \pm SD of Triglyceride in cases and controls.

Table 9. Mean and SD of HDL (High-Density Lipoprotein) in healthy controls and cases.

\begin{tabular}{l|c|c|c} 
& Group (n-100) & Mean \pm SD & p value \\
\hline \multirow{2}{*}{ HDL } & Controls (n-50) & $37.96 \pm 8.55$ & 0.054
\end{tabular}

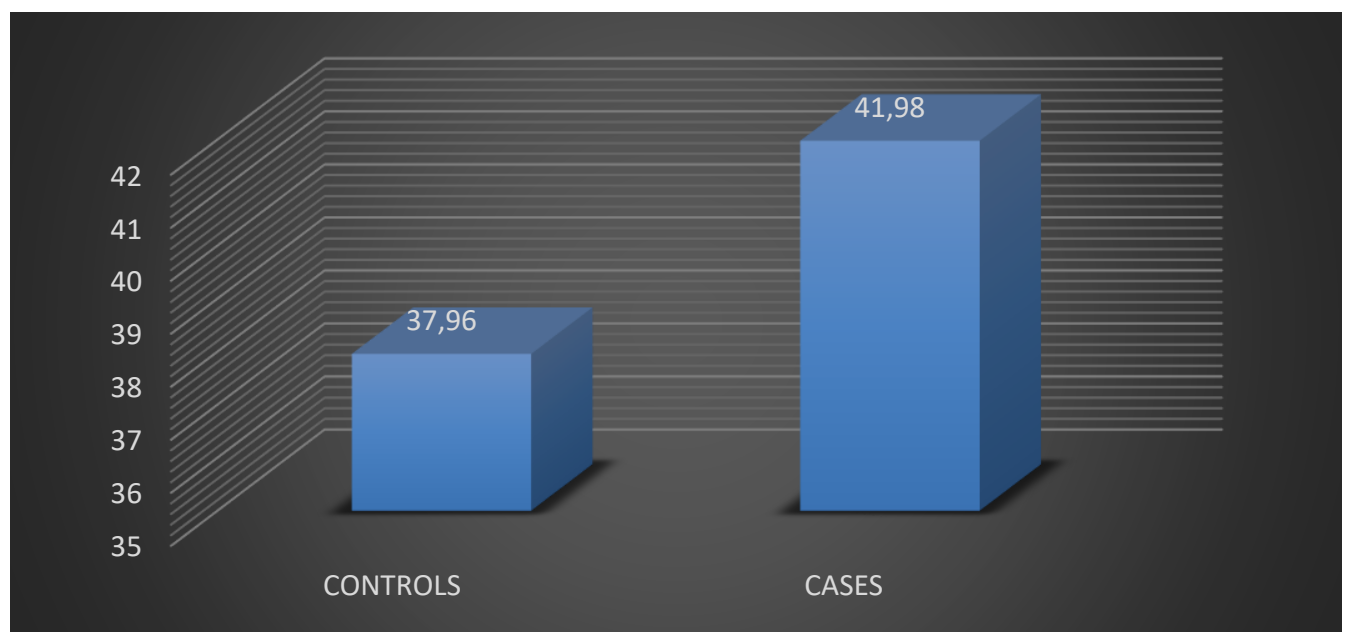

Figure 5. Mean \pm SD of HDL in cases and controls.

Table 10. Mean and SD of LDL (Low-Density Lipoprotein) in healthy controls and cases.

\begin{tabular}{|c|c|c|c|}
\hline & & CD & \\
\hline \multirow[t]{2}{*}{ LDL } & Controls (n-50) & $99.74 \pm 29.18$ & \multirow{2}{*}{0.193} \\
\hline & Cases (n-50) & $127.99 \pm 37.72$ & \\
\hline
\end{tabular}

It was observed that mean T3 in cases $(<0.003)$ was highly significant compared to controls. The table shows that in controls, Mean \pm SD $(1.10 \pm 0.31)$ and in cases Mean \pm SD $(4.31 \pm 7.43)$ p-value was $(0.003)$, which is highly significant (Figure 8, Table 12). It was observed that mean T4 in cases $(<0.000)$ was highly significant compared to controls. The table shows that in controls Mean \pm SD $(7.25 \pm 1.72)$ and in cases Mean \pm SD $(3.43 \pm 1.03)$, the pvalue was (0.000), which is highly significant (Figure 9, Table 13). 


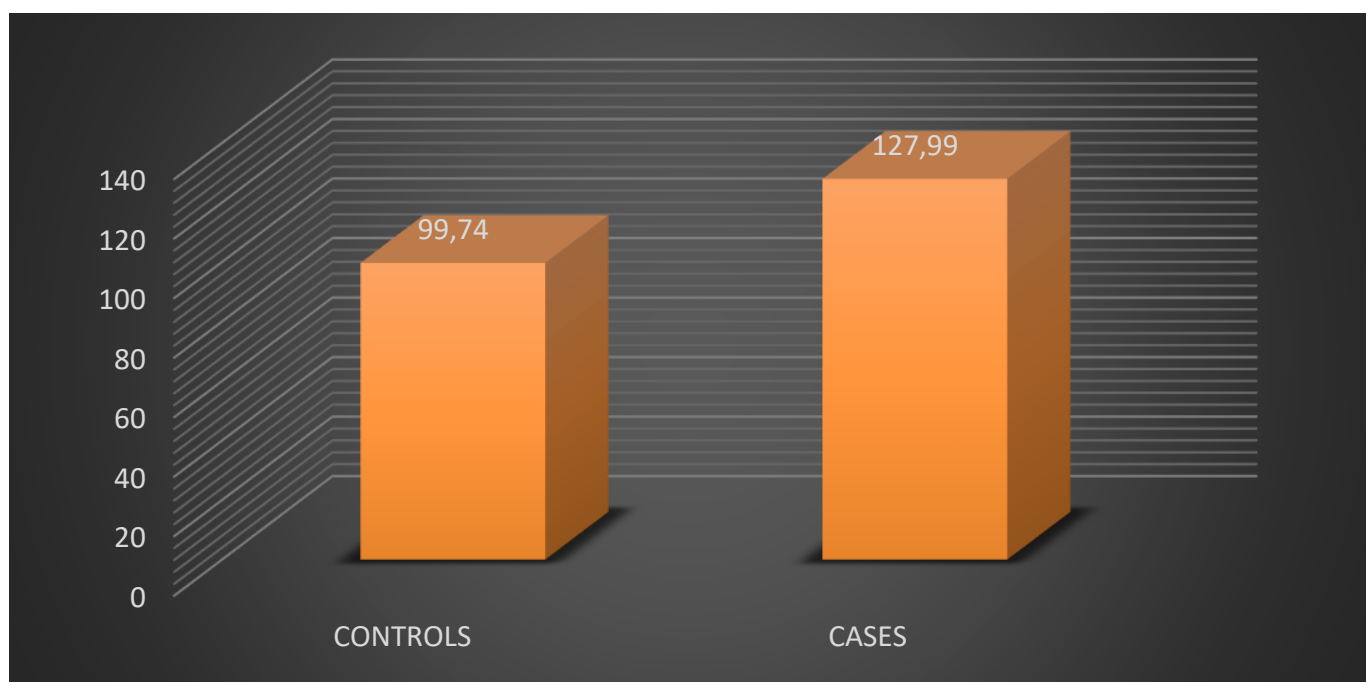

Figure 6. Mean \pm SD of LDL in cases and controls.

Table 11. Mean and SD of VLDL (Very Low-Density Lipoprotein) in healthy controls and cases.

\begin{tabular}{|c|c|c|c|}
\hline & Group (n-100) & Mean \pm SD & p value \\
\hline \multirow[t]{2}{*}{ VLDL } & Controls (n-50) & $25.08 \pm 3.82$ & \multirow[t]{2}{*}{$<0.000 * *$} \\
\hline & Cases (n-50) & $31.55 \pm 11.68$ & \\
\hline
\end{tabular}

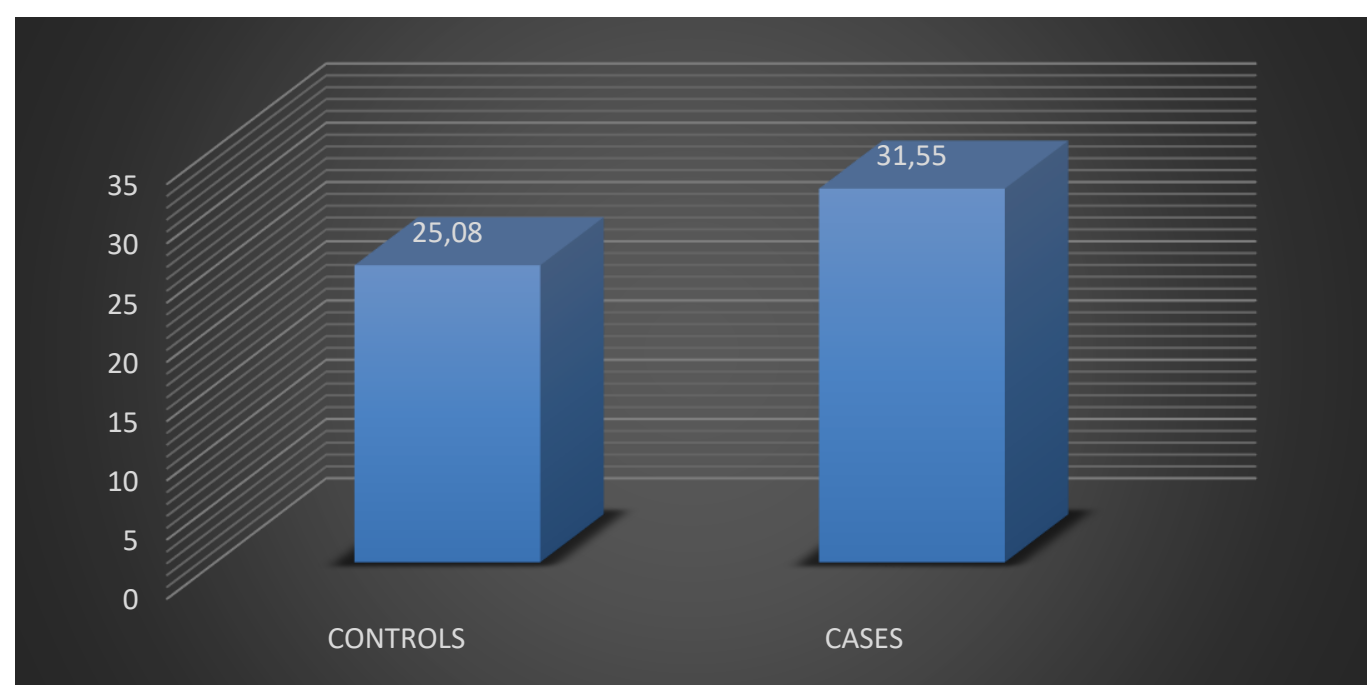

Figure 7. Mean \pm SD of VLDL in cases and controls.

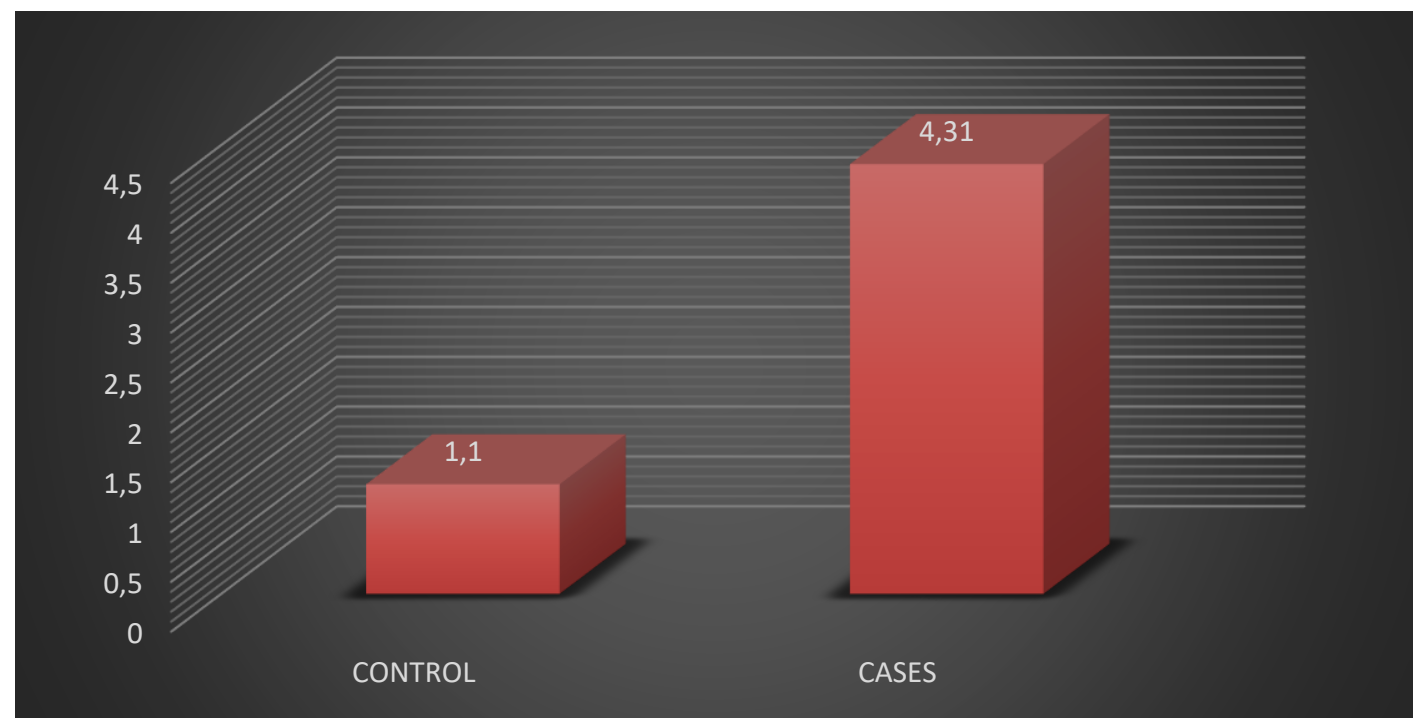

Figure 8. Mean \pm SD of T3 in cases and controls. 


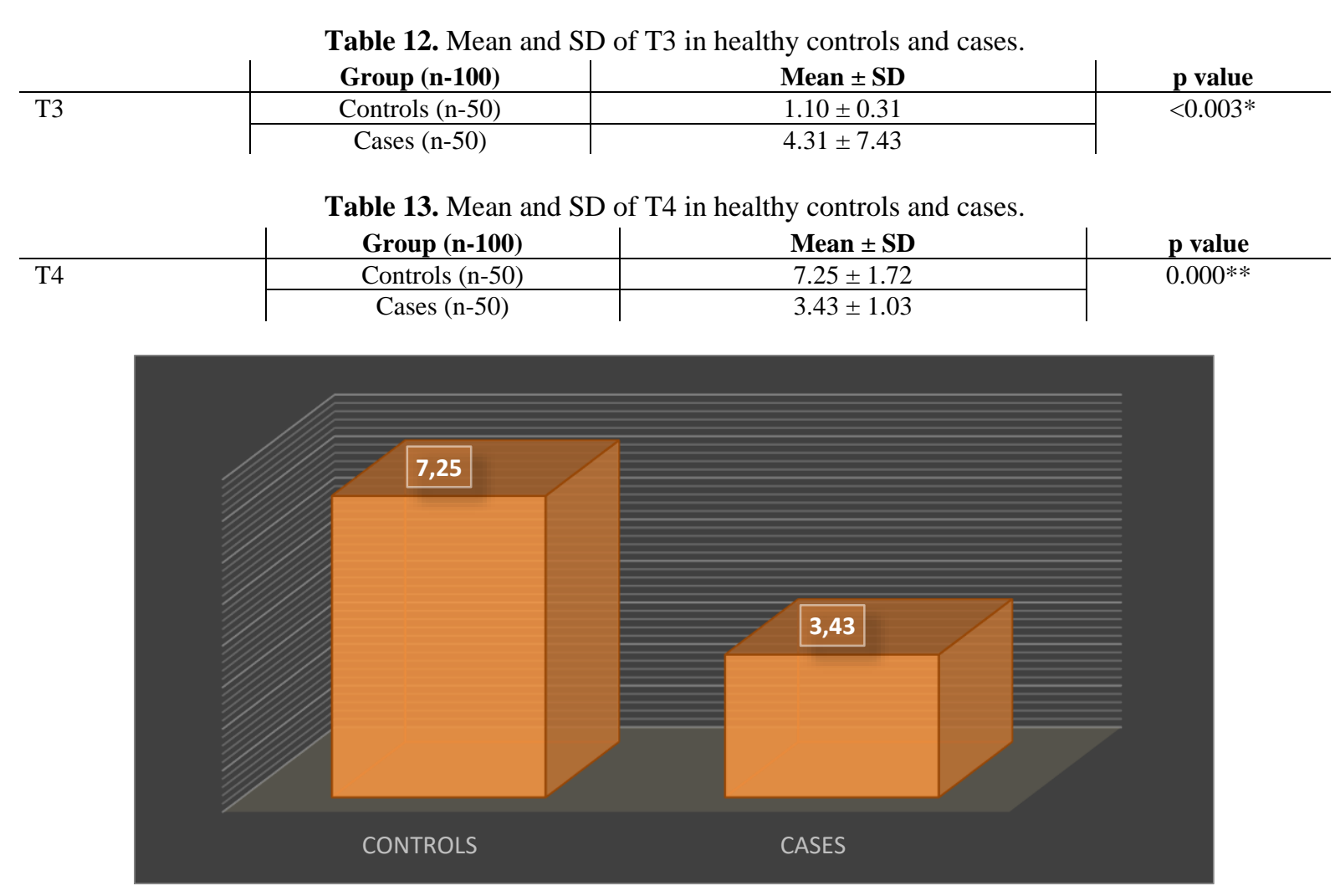

Figure 9. Mean \pm SD of T4 in cases and controls.

\section{Discussion.}

The thyroid is the most general endocrine disorder and is related to thyroid hormones [16]. Such disorders have their association with either an increased (hyperthyroidism) or decreased activity (hypothyroidism) of the thyroid gland [17]. The chances of thyroid dysfunction are mainly seen in female cases and increased with age [18]. Hypothyroid suffering persons have decreased myocardial contractility, cardiac output, and peripheral oxygen consumption, increasing peripheral vascular resistance. The increased peripheral resistance can lead to changes in renal hemodynamics like decreased renal blood flow and reduced glomerular filtration rate. Therefore, certain substances like creatinine kinase, creatinine, and others are reduced clearance in hypothyroidism [19].

In CKD patients, many alterations have been reported because of changes in thyroid status. There is a significant decrease in T3, T4 levels in patients with kidney disease in cases compared to controls. This was similar to our research. In our study also, we found alterations in creatinine \& thyroid hormone status. Patients with hypothyroidism had increased serum creatinine levels due to renal disease and increased total serum creatine kinase activity due to skeletal muscle dysfunction [20]. The decrease in renal plasma flow and glomerular filtration rate (GFR) that accompany hypothyroidism are believed to be related to the generalized hyperdynamic state of the circulatory system in hypothyroidism. Skeletal muscles may be the major source of increased plasma CK activity in hypothyroidism. Creatinine activity is considered to be a sensitive and excellent biochemical marker for the diagnosis of kidney diseases. An increase in the level of these parameters represents an index of cellular necrosis and tissue damage. Hypothyroidism is common in patients with kidney disorders [21]. The creatinine level increases due to rising levels of creatine kinase in hypothyroidism due to decreased GFR. The decrease in T3 level has been found to be associated with markers of inflammation like hs CRP, IL-6, malnutrition, and increased endothelial dysfunction. In our 
study result, the level of creatinine increases with an increase in hypothyroidism. There are some previous studies of creatinine, which show a resemblance to our present study results.

Our study showed a significant positive correlation between serum cholesterol and serum creatinine in hypothyroid patients. Presently, an explanation of various impacts of hypothyroidism towards impaired health attains special importance in modern medicine. Thyroid dysfunction has an impact on various organ systems of the body. The present study was carried out to see the impact of thyroid disorder on serum cholesterol. In kidney disease, patients' high triglycerides have an important role to play. Cholesterol levels increase in these patients. There is an increase in triglyceride-rich lipoproteins in such patients, especially VLDL, as decreased endothelium bound lipoprotein levels and an increase in apolipoproteins. They attach to the endothelial surface and hydrolyze the triglycerides. In kidney failure patients, there is downregulation of lipoproteins. The lipoproteins are not cleared properly and they tend to accumulate in the tissues. Therefore, they promote atherosclerosis and kidney damage.

\section{Conclusions}

The present study explains various impacts of hypothyroidism contributing to impaired health attains special importance for its screening in medical practice. Many studies have been carried out to elucidate a better, more reliable, and cost-effective method for the assessment of thyroid all over the world, including India. However, there is a paucity of documentation in India regarding comparing different parameters of hypothyroidism such as TSH and Creatinine, cholesterol.

The present study was conducted in the department of biochemistry in fifty hypothyroid male and female cases and 50 healthy controls. The majority of the cases were in the age group 32-60 years and controls 18-31years. Following are the mean values of different parameters of hypothyroid patients estimated in the study groups. In our study, we carried out some other investigations along with our main parameters.

Table 14. Mean value of different parameters in our study.

\begin{tabular}{l|l|l} 
Tests & Cases & Controls \\
\hline TSH & $3.47 \pm 1.30$ & $18.44 \pm 14.57$ \\
\hline Serum Cholesterol & $202.62 \pm 47.16$ & $161.82 \pm 25.441$ \\
\hline FBS & $107.74 \pm 23.85$ & $96.17 \pm 10.42$ \\
\hline TG & $153.58 \pm 47.03$ & $124.002 \pm 16.77$ \\
\hline HDL & $41.98 \pm 10.91$ & $37.96 \pm 8.55$ \\
\hline LDL & $127.99 \pm 37.72$ & $99.74 \pm 29.18$ \\
\hline VLDL & $31.55 \pm 11.68$ & $25.08 \pm 3.82$ \\
\hline T3 & $4.31 \pm 7.43$ & $1.10 \pm 0.31$ \\
\hline T4 & $3.43 \pm 1.03$ & $7.25 \pm 1.72$
\end{tabular}

In the mean values of cholesterol, there was a significant difference between serum cholesterol of hypothyroid cases and controls with a p-value $<0.001$. There was a significant difference between serum TSH of hypothyroid cases and controls with a p-value $<0.000$.

We found that, in other investigations, FBS, TG, VLDL, Uric Acid, T3 \& T4, the pvalue was found significant among cases and controls. These results are similar to a study by G. A. Kaysen. According to both his study and ours, cholesterol and lipoprotein levels are increased in patients with kidney disease and hypothyroidism. The findings are summarized as the cholesterol levels in hypothyroid patients also were increased. A statistically highly 
significant positive correlation was found between the level's serum TSH and serum creatinine in the patients of hypothyroidism. A statistically significant positive correlation was found between age and serum TSH in patients with hypothyroidism. A statistically highly significant positive correlation was found between serum TSH levels in female patients compared to the male patients in hypothyroidism. A statistically highly significant positive correlation was found between the levels of serum FBS, TG, VLDL, t3 \& t4 in cases compared to the controls in hypothyroidism.

In the present study, we concluded that TSH level is increased and T3 and T4 levels are decreased in hypothyroid patients, creatinine, and cholesterol levels are increased in hypothyroid patients. We observed that there is an increase in TSH levels as age increases. We can say that any change in thyroid hormone levels alters skeletal muscles' functioning and decreases renal perfusion and filtration capacity. In hypothyroidism, renal dysfunction occurs before skeletal muscle involvement. The increased serum levels of creatinine in hypothyroidism maybe because of skeletal muscle dysfunction. Abnormal thyroid hormone profile in blood without any underlying disorder of thyroid gland can occur in chronic renal disorders, causing difficulty and errors in their interpretation. Our data highlight that CKD leads to a significant lowering of free thyroid hormone levels, with a reduction correlating with the severity of the renal disease. This project emphasizes the importance of thyroid hormone estimation and exercising adequate care in interpreting their results in patients with CKDs. Further larger studies evaluating the clinical significance of thyroid hormone status in CKD patients would enhance our understanding of the subject [15].

\section{Funding}

None.

\section{Acknowledgments}

The team of authors thanks to the Department of Biochemistry in collaboration with the Department of General Medicine, M.M. Institute of Medical Sciences and Research, Mullana, Ambala, to research and survey the patient's diagnosis and research.

\section{Conflicts of Interest}

The authors declare no conflict of interest.

\section{References}

1. Chiovato, L.; Magri, F.; Carlé, A. Hypothyroidism in Context: Where We've Been and Where We're Going. Advances in therapy 2019, 36(Suppl 2), 47-58, https://doi.org/10.1007/s12325-019-01080-8.

2. Berta, E.; Lengyel, I.; Halmi, S.; Zrínyi, M.; Erdei, A.; Harangi, M.; Bodor, M.; Dénes Páll, Endre V. Nagy. Hypertension in Thyroid Disorders. Frontiers in Endocrinology 2019, 10, https://doi.org/10.3389/fendo.2019.00482.

3. Bekkering, G.E.; Agoritsas, T.; Lytvyn, L.; Heen, A.F.; Feller, M.; Moutzouri, E.; Vermandere, M. Thyroid hormones treatment for subclinical hypothyroidism: a clinical practice guideline. BMJ 2019, 365, 12006, https://doi.org/10.1136/bmj.12006.

4. McGrowder, D.A.; Fraser, Y.P.; Gordon, L.; Crawford, T.V.; Rawlins, J.M. Serum creatine kinase and lactate dehydrogenase activities in patients with thyroid disorders. Niger J Clin Pract 2011, 14, 454-459, https://doi.org/10.4103/1119-3077.91755. 
5. Lin, H.H.; Tang, M.G. Thyroid hormone upregulates Na, K-ATPase alpha and beta mRNA in primary culture of proximal tubule cells. Life Science 1997, 60, 375-382, https://doi.org/10.1016/s0024-3205(96)00661-3.

6. Gupta, S.K.; Ghalaut, V.S.; Jain, A. Manual of practical biochemistry 2010 (2nd edition), 93-94, https://www.abebooks.co.uk/Manual-Practical-Biochemistry-MBBS-S.K-Gupta/16648318976/bd.

7. Hollander, J.G.den.; Wulkan, R.W.; Mantel, M.J.; Berghout, A. Correlation between severity of thyroid dysfunction and renal function. Clin Endocrinol 2005, 62, 423-427, https://doi.org/10.1111/j.13652265.2005.02236.x.

8. Wyss, M.; Kaddurah-Daouk, R. Creatine and creatinine metabolism. Physiol Rev. 2000, 80, 1107-213, https://doi.org/10.1152/physrev.2000.80.3.1107.

9. Altay, M.; Duranay, M.; Ceri, M. Rhabdomyolysis due to hypothyroidism. Nephrol Dialysis Transplantation 2005, 20, 847-848, https://doi.org/10.1093/ndt/gfh745.

10. Karanikas, G.; Schutz, M.; Szabo, M.; Becherer, A.; Wiesner, K.; Dudczak, R.; Kletter K. Isotopic renal function studies in severe hypothyroidism and after thyroid hormone replacement therapy. American Journal of Nephrology 2004, 24, 41-45, https://doi.org/10.1159/000075628.

11. Giordano, N.; Santacroce, C.; Mattii, G.; Geraci, S.; Amendola, A.; Gennari, C. Hyperuricemia and gout in thyroid endocrine disorder. Clin Exp Rheumatol 2001, 19, 661-665, https://pubmed.ncbi.nlm.nih.gov/11791637.

12. Kreisman, S.H.; Hennessey, J.V. Consistent reversible elevations of serum creatinine levels in severe hypothyroidism. Arch Intern Med. 1999, 159, 79-82, https://doi.org/10.1001/archinte.159.1.79.

13. Schmid, C.; Brandle, M.; Zwimpfer, C.; Zapf, J.; Wiesli, P. Effect of thyroxine replacement on creatinine, insulinlike factor 1, acid-labile subunit, and vascular endothelial growth factor. Clin Chem 2004, 50, 228-31, https://doi.org/10.1373/clinchem.2003.021022.

14. Erickson, A.R.; Enzenauer, R.J.; Nordstrom, D.M.; Merenich, J.A. The prevalence of hypothyroidism in gout. Am J Med. 1994, 97, 231-234, https://doi.org/10.1016/0002-9343(94)90005-1.

15. Srivastava, S.; Rajput, J.; Shrivastava, M.; Chandra, R.; Gupta, M.; Sharma, R. Correlation of thyroid hormone profile with biochemical markers of renal function in patients with undialyzed chronic kidney disease. Indian J Endocr Metab 2018, 22, 316-320, https://doi.org/10.4103/ijem.IJEM_475_17.

16. Pal, R.; Bhadada, S.K. Managing common endocrine disorders amid COVID-19 pandemic. Diabetes \& Metabolic Syndrome: Clinical Research \& Reviews 2020, 14, 767771, https://doi.org/10.1016/j.dsx.2020.05.050.

17. Deepika, M. A Prognostic Thyroid Disorder analysis based on Thyroid Test Measure with ECG. International Conference on Advances in Electrical, Computing, Communication and Sustainable Technologies 2021, 1-8, https://doi.org/10.1109/ICAECT49130.2021.9392450.

18. Unuane, D.; Velkeniers, B. Impact of thyroid disease on fertility and assisted conception. Best Pract Res Clin Endocrinol Metab. 2020, 34, 101378, https://doi.org/10.1016/j.beem.2020.101378.

19. Baird, M.F.; Graham, S.M.; Baker, J.S.; Bickerstaff, G.F. Creatine-Kinase- and Exercise-Related Muscle Damage Implications for Muscle Performance and Recovery. Journal of Nutrition and Metabolism 2012, 2012, https://doi.org/10.1155/2012/960363.

20. Brancaccio, P.; Lippi, G.; Maffulli, N. Biochemical markers of muscular damage. Clin Chem Lab Med. 2010, 48, 757-67, https://doi.org/10.1515/CCLM.2010.179.

21. Ranka, R.; Mathur, R. Serum Creatine phosphokinase in thyroid disorders. Indian J Clin Biochem. 2003, 18, 107-10, https://doi.org/10.1007/BF02867676. 